\title{
Stratosphere-troposphere exchange (STE) in the vicinity of North Atlantic cyclones
}

\author{
P. Reutter ${ }^{1}$, B. Š Kerlak ${ }^{2}$, M. Sprenger ${ }^{2}$, and H. Wernli ${ }^{2}$ \\ ${ }^{1}$ Institute for Atmospheric Physics, University of Mainz, Mainz, Germany \\ ${ }^{2}$ Institute for Atmospheric and Climate Science, ETH Zurich, Zürich, Switzerland \\ Correspondence to: P. Reutter (preutter@uni-mainz.de) \\ Received: 18 December 2014 - Published in Atmos. Chem. Phys. Discuss.: 27 January 2015 \\ Revised: 1 August 2015 - Accepted: 10 September 2015 - Published: 2 October 2015
}

\begin{abstract}
It is well known that the storm tracks are a preferred region of stratosphere-troposphere exchange (STE), but a systematic and climatological investigation of the connection between cyclones and STE has not yet been performed. We use two ERA-Interim climatologies of STE and cyclones for the years 1979-2011 to quantify the amount of STE that occurs during the life cycle of North Atlantic cyclones. A Lagrangian method serves to identify individual STE events, and a sophisticated cyclone identification tool detects cyclones, their shape and size from the sea-level pressure (SLP) field and from geopotential height anomalies at $300-700 \mathrm{hPa}$. Combining the two data sets reveals that roughly $50-60 \%$ of the total STE in the North Atlantic occurs in the vicinity of cyclones and that both downward and upward fluxes of mass across the tropopause (STT and TST, respectively) are more intense in deeper cyclones (lower minimum SLP) compared to less intense cyclones. In summer, STT and TST in the vicinity of cyclones are almost equal; in the other seasons, STT is larger by $25-60 \%$. Compared to climatology, cross-tropopause mass fluxes are enhanced by a factor of about 1.29 and 1.06 for STT and TST, respectively, when a cyclone is present. On average, STE is strongest during the mature phase of cyclones, i.e., in a $24 \mathrm{~h}$ time window around the time of maximum intensity. Systematic patterns of exchange locations relative to the cyclone centre are identified via composite analysis and shed light on the different characteristics of STT and TST. During cyclone intensification and in the mature stage, TST is mainly confined to the cyclone centre, whereas STT occurs mainly in a region further southwest. During the decay of the cyclones, both STT and TST are most frequent close to the cyclone centre, in a region with a fairly low tropopause.
\end{abstract}

\section{Introduction}

The exchange of air across the extratropical tropopause plays an important role for the chemical composition of the stratosphere and the troposphere. For instance, the injection of stratospheric air into the troposphere can enhance the ozone concentration in the troposphere significantly (e.g., Danielsen, 1968; Stevenson et al., 2006), even down to the boundary layer (Johnson and Viezee, 1967; Lefohn et al., 2011; Lin et al., 2012). On the other side, the amount of water vapour in the extratropical lower stratosphere can strongly increase when tropospheric air is transported across the tropopause (e.g., Krebsbach et al., 2006). Even polluted air from the boundary layer can be transported into the extratropical lower stratosphere (e.g., Arnold et al., 1997; Chen et al., 2012). It is therefore relevant to understand and quantify the physical processes leading to and the flow features associated with stratosphere-troposphere exchange (STE) in the extratropics.

In this study, as in many previous studies (e.g., Holton et al., 1995; Stohl et al., 2003), the extratropical tropopause is defined as the 2-pvu isosurface of potential vorticity (PV) $\left(1 \mathrm{pvu}=10^{-6} \mathrm{Km}^{2} \mathrm{~kg}^{-1} \mathrm{~s}^{-1}\right)$. Therefore, as a consequence of the material conservation of PV for adiabatic and frictionless flow (Ertel, 1942), STE must be associated with processes that lead to a material production or destruction of PV such as cloud microphysical processes (e.g., latent heating due to condensation), radiation, or friction (e.g., associated with turbulence). Furthermore, these physical processes occur preferentially in the vicinity of certain dynamical flow features. This distinction between processes and features is important: processes refer to the physical mecha- 
nisms that change $\mathrm{PV}$, whereas features refer to the meteorological flow setting wherein these processes (likely a combination thereof) occur. In the last decades, the processes and flow structures associated with STE have been intensively investigated, as discussed in the review articles by Reiter (1975); Holton et al. (1995); and Stohl et al. (2003). Different studies highlighted different processes to be relevant for STE, which indicates large case-to-case variability and a general lack of understanding about the relevance of processes leading to STE. These processes include turbulence by shear instability (Shapiro, 1980; Traub and Lelieveld, 2003), the breaking of gravity waves (Whiteway et al., 2003; Lane and Sharman, 2006), cloud diabatic processes in stratiform and convective clouds (Wirth, 1995; Poulida et al., 1996), and radiative cooling due to strong vertical humidity gradients near the tropopause (Zierl and Wirth, 1997). Regarding flow features, a strong focus has been on STE in tropopause folds that occur near the polar and subtropical jets (see Škerlak et al. (2015), and references therein). Sprenger et al. (2003) compiled a 1-year climatology of folds and showed that for STE in the subtropics, folds are highly important (around $60 \%$ of total STE occurs near folds), whereas in the extratropics, where folds are comparatively rare, they only account for about $20 \%$ of total STE. Using a similar approach, Sprenger et al. (2007) quantified the importance of isentropic PV streamers and cutoffs, resulting from Rossby wave breaking, for STE and found that about $70 \%$ of all STE events between 290 and $350 \mathrm{~K}$ occur in the vicinity of such a PV feature ${ }^{1}$. In the current study, the occurrence of STE in the feature category of extratropical cyclones is quantified.

Several studies in the last decade used global reanalysis data to provide a climatological picture of STE (see Škerlak et al. (2014), and references therein). These climatologies indicate that the distribution of STE in the extratropics has a strong seasonal cycle and pronounced geographic variability. In particular, it was shown that maxima of STE are located over the storm track regions in the North Atlantic and North Pacific during all seasons (except summer) with an averaged mass flux of approximately $500 \mathrm{~kg} \mathrm{~km}^{-2} \mathrm{~s}^{-1}$ from the stratosphere to the troposphere (STT) and approximately $300 \mathrm{~kg} \mathrm{~km}^{-2} \mathrm{~s}^{-1}$ in the opposite direction (TST) (Škerlak et al., 2014). This indicates qualitatively that STE is likely enhanced in the vicinity of cyclones compared to the climatological average.

Previous studies estimated the amount of STE in the vicinity of individual cyclones by considering idealized baroclinic waves (Bush and Peltier, 1994) or real case studies (e.g., Bourqui, 2006). In some of these studies the results were then extrapolated to the global scale. Due to the considerable variability of cyclone life-cycles and their associated STE pro-

\footnotetext{
${ }^{1}$ Note that the different features categories are not mutually exclusive; for instance, a tropopause fold can occur as part of a PV cutoff, and therefore the sum of the percentages associated with different features can exceed $100 \%$.
}

cesses, this approach is highly uncertain, indicating the need for a systematic climatological investigation. However, these case studies nicely reveal the complex spatio-temporal structures and diverse physical processes associated with STE in cyclones, as briefly summarized here. A first pioneering case study of STE in an extratropical cyclone by Lamarque and Hess (1994) considered a moderately intense winter cyclone over the US and concluded that diabatic processes were much more important than diffusive processes. Intense TST occurred mainly in the western part of the associated upperlevel PV structure and STT in the eastern part (i.e., above the cyclone warm sector). A second pioneering case study considered an explosively deepening cyclone (Spaete et al., 1994) and found a similar spatial distribution of STT and TST relative to the cyclone centre. For a North Atlantic winter cyclone, also of moderate intensity, Wernli and Davies (1997) found intense STT during the $24 \mathrm{~h}$ of cyclone intensification and much weaker STT during the previous and subsequent days. TST was generally weaker but increased with time and balanced STT on the last day of the cyclone life cycle. TST mainly occurred near the cyclone centre and further north, whereas STT peaked to the rear of the cyclone and along the cold front. Wirth and Egger (1999) used different methods to quantify STE in a decaying Mediterranean cutoff cyclone in summer and showed that convective heating in the centre of the cyclone was mainly responsible for intense STT. Later, Bourqui (2006) considered a similar system in autumn and confirmed the dominance of STT over TST for cyclones associated with an upper-level cutoff. Another study on STE in a cutoff cyclone over Northeast China by Liu et al. (2013) used satellite data to quantify the irreversible transport of stratospheric ozone into the troposphere. For a North Atlantic winter cyclone and using a passive tracer in a mesoscale model, Gray (2003) also highlighted the role of deep convection for producing intense STT, however along the long trailing cold front. This is in qualitative agreement with the study by Brioude et al. (2006), who looked at STE in the extratropical transition of tropical storm Arthur and pointed to the possible role of deep convection for mixing stratospheric air in folded regions irreversibly into the troposphere. Also, Cooper et al. (2002) considered several warm season North Atlantic cyclones and emphasized the dry intrusion airstream, which often goes along with a tropopause fold, as a preferred region for STT. In contrast, Kowol-Santen et al. (2000) concluded that turbulence in a tropopause fold was more important for STE than cloud diabatic processes. Their study object was a pronounced PV streamer in winter, which broke up into an upper-level cutoff and was associated at its northern end with a surface cyclone over Iceland and further south with a mesocyclone near Portugal. Also using a Lagrangian approach, Sigmond et al. (2000) quantified STE in a stationary North Sea spring cyclone and found STT mainly in a folded upper-level trough and TST in the upper-level ridge. For an intense North American cyclone in early winter, Olsen and Stanford (2001) used trajectories and 
identified STT due to latent heating in the cyclone centre and due to turbulence further south. This brief summary of case studies of STE in various types of cyclones very clearly highlights the great case-to-case variability of the main processes leading to STE and their preferred location within the cyclonic system. Also the quantitative estimates of STE provided by these case studies vary considerably. This corroborates the need for a more robust, climatological analysis of the quantitative link between STE and cyclones.

To this end, we combine a climatology of extratropical cyclones based on an extended version of the cyclone identification approach by Wernli and Schwierz (2006) (see Sect. 2.2.) with a recently published climatology of STE (Škerlak et al., 2014). By combining these climatologies - which are both derived from the ERA-Interim reanalysis data set provided by the European Centre of Medium-Range Weather Forecasts (ECMWF) (Dee et al., 2011) - the following questions can be addressed:

- What percentage of the total STT and TST mass flux occurs in the vicinity of North Atlantic cyclones? What is the regional and seasonal variability of this number?

- Does STT and TST associated with an individual cyclone depend on its intensity, as expressed by its minimum sea level pressure (SLP)?

- Are there, on average, preferred locations for STT and TST within cyclones?

- What is the timing of STE with respect to the evolution of the cyclone, i.e., is STE more intense during cyclone intensification, in the mature stage, or during decay?

Answering these questions requires sophisticated methods (e.g., to relate individual STE events to cyclones and to a specific phase of their evolution), which are presented in Sect. 2. Section 3 first shows an illustrative case study of a cyclone and its associated STE, and in Sect. 4 the findings of combining the cyclone and STE climatologies are presented. In Sect. 5 the results are summarized, discussed and an outlook for future studies is given.

\section{Data and methods}

\subsection{ERA-Interim}

We use the ERA-Interim reanalysis data set from the European Centre of Medium-Range Weather Forecasts (ECMWF) (Dee et al., 2011). It is based on a 4-D-Var data assimilation technique and is available every $6 \mathrm{~h}$. In this study, we analyse the first 33 years from 1979 to 2011. The data are available at a T255 spectral grid which corresponds to approximately $80 \mathrm{~km}$. We interpolate all data on a regular grid with $1^{\circ}$ resolution in the zonal and meridional directions. The 60 vertical hybrid sigma-pressure model levels reach from the surface up to $0.1 \mathrm{hPa}$. We compute secondary variables such as potential vorticity (PV) and potential temperature $(\Theta)$ directly on the model levels.

\subsection{Cyclone identification tool}

Extratropical cyclones are identified based on a vertical extension of the method described in Wernli and Schwierz (2006). As in this former study, cyclones are defined and tracked based upon the identification of local minima of SLP. However, in contrast to the former study, where the twodimensional shape of the cyclone was identified by the outermost closed SLP contour, here in addition contours of negative geopotential height anomalies at 700,500 and $300 \mathrm{hPa}$ are considered to the define the cyclone shape. This technique is briefly described in the next paragraphs. It serves to obtain a two-dimensional "cyclone region" at every 6-hourly time step along a cyclone track, which also reflects the structure of the cyclone-trough system in the middle and upper troposphere and is therefore ideally suited for attributing STE to cyclones.

First SLP contours are considered at $0.5 \mathrm{hPa}$ intervals between 920 and $1050 \mathrm{hPa}$ and the regions within closed isobars that encircle a local SLP minimum are accepted as cyclone regions if they additionally fulfil the following criteria: (i) the enclosed SLP minimum is not located over topography exceeding $1500 \mathrm{~m}$ height; and (ii) the length of the enclosing contour is smaller than $7500 \mathrm{~km}$, hence excluding unrealistically large features that typically go along with very flat SLP distributions. The first criterion makes sure that spurious SLP minima due to reduction to sea level are excluded from the climatology. The resulting cyclone climatology is a data set of pairs $\left(C_{\min }, C_{\text {reg }}\right)$ where $C_{\min }$ is defined as the location (longitude and latitude) of the cyclone centre and $C_{\text {reg }}$ is a region attributed to this cyclone, defined so far only by the outermost enclosing SLP contour and represented by a $0 / 1$ label field on the $1^{\circ}$ resolution grid. $C_{\min }$ is used for cyclone tracking (see below) and for the composite analysis in Sect. 3.4.

The cyclone region $C_{\text {reg }}$ is now modified using anomalies of geopotential height at 700, 500 and $300 \mathrm{hPa}$. These anomalies were calculated at every grid point as deviations from the 10-day running mean. In most cases this field shows negative values near cyclones identified from the SLP field. At 500 and $700 \mathrm{hPa}$ these negative anomalies typically correspond to the location of the upper-level trough that is essential for the formation of the cyclone. In rare cases where no upper-level trough is associated with the surface cyclone, there would be no or just a weak negative geopotential height anomaly at upper levels. Now similarly to our contour search with the SLP field, closed contours of the geopotential height anomaly field are identified at the three pressure levels. Again a maximum contour length of $7500 \mathrm{~km}$ limits the size of the negative anomaly features. The cyclone region $C_{\text {reg }}$, defined so far by the SLP feature alone, is horizontally extended if it 
overlaps with an anomaly feature at $700 \mathrm{hPa}$. The extended region $C_{\text {reg }}$ now encompasses the union of features at both levels. Then, in the next steps, the same procedure is repeated for 500 and $300 \mathrm{hPa}$, allowing the cyclone region to horizontally grow if the anomaly features at the higher level overlaps with the so-far defined region $C_{\text {reg. }}$. The result of this procedure is the final two-dimensional cyclone region $C_{\text {reg }}$, which encloses and is larger than the cyclone area identified from the SLP field alone. This method is strongly flow-dependent, i.e., it can distinguish between smaller and larger cyclones in comparison to a more static approach, which would use, e.g., a constant cyclone radius.

It is then straightforward to attribute every STE event unambiguously to a cyclone. An STE event belongs to a cyclone if it occurs within its associated cyclone region. However, a complication arises for multi-centre cyclones, where nearby local pressure minima are found within the same enclosing isobar. Since the two minima likely belong to two different cyclone tracks, it is important, in this case, to split the cyclone region between the different centres according to their relative depth. Note that multi-centre cyclones also bring a slight ambiguity into the definition of the cyclone region $C_{\text {reg }}$ because the horizontal "growing" algorithm, as defined above by the overlap criterion, must decide to which cyclone centre the extension is attributed. Here, we adopt the pragmatic approach that the maximum overlap decides.

Finally, as mentioned above, cyclone centres at individual times are combined into time-continuous cyclone tracks. To this end we apply the relatively simple approach described in Wernli and Schwierz (2006), with some refinements that were already used for the IMILAST cyclone identification and tracking intercomparison (Neu et al., 2013): (i) the allowance and bridging of $12 \mathrm{~h}$ intervals without cyclones with closed SLP contours; and (ii) a more sophisticated "first guess" forward-projection of the cyclone movement, based on the preceding cyclone path. The cyclone tracks are important for this study to determine the overall deepening of the cyclone, to relate the deepening to the associated STE, and to distinguish between the deepening, the mature (time of SLP minimum $\pm 12 \mathrm{~h}$ ), and finally the decaying phase of a cyclone's life cycle.

\subsection{STE identification with LAGRANTO}

Our study uses the Lagrangian methodology introduced by Wernli and Bourqui (2002) and further refined by Škerlak et al. (2014) to quantify STT and TST. It is based on the dynamical tropopause definition, namely the combination of the \pm 2 pvu and $380 \mathrm{~K}$ isosurfaces (whichever is lower) (Hoskins et al., 1985; Holton et al., 1995). This definition allows to detect STE using the PV and $\Theta$ fields along kinematic air parcel trajectories. We start trajectories on a dense grid with $80 \mathrm{~km}$ horizontal and $30 \mathrm{hPa}$ vertical grid spacing and compute them for $24 \mathrm{~h}$. STT and TST can then be identified in the extratropics as transitions from $|\mathrm{PV}|>2 \mathrm{pvu}$ to
$|\mathrm{PV}|<2$ pvu, or vice versa, and similarly in the tropics by considering crossings of the $380 \mathrm{~K}$ surface. To filter out spurious exchange events due to diabatically or frictionally produced low-level PV anomalies, we additionally use a 3-Dlabelling algorithm presented in Škerlak et al. (2014) to objectively separate the stratosphere from the troposphere in challenging situations (see also Škerlak et al., 2015). The selected STE trajectories are then extended for 4 days in both directions and it is checked whether they stay at least $48 \mathrm{~h}$ on both sides of the tropopause, thus filtering out "transient" exchange events (Wernli and Bourqui, 2002; Škerlak et al., 2014).

\subsection{Combination of cyclone and STE data}

To compute the STE mass flux associated with a specific cyclone, we select the STE trajectories that cross the tropopause within the cyclone area defined by the procedure explained above. Since each trajectory represents a certain mass $\Delta m \approx$ $\frac{1}{g} \Delta x \Delta y \Delta p=6.52 \times 10^{11} \mathrm{~kg}$, this allows us to compute mass fluxes in both directions separately $(\Delta x, \Delta y$ and $\Delta p$ represent the spacing of the trajectory starting points in the horizontal and vertical directions, respectively). Note that this approach is fully dynamic in the sense that for a small cyclone the STE event must occur close to the cyclone centre in order to be associated with the cyclone, whereas for large cyclones an STE event can also be associated with the cyclone if its location is fairly distant from the cyclone centre. The adopted definition of the cyclone area is rather restrictive, i.e., regions along a trailing cold front outside of the closed contours are not considered as part of the cyclone area. Therefore our estimates of STE attributed to cyclones should be regarded as a conservative estimate or lower bound. Also, for every STE event classified as associated to a cyclone, the coordinates relative to the cyclone centre are determined, which later allows producing composites of STT and TST relative to the cyclone centre.

\section{Introductory case study: cyclone "Xynthia" in February 2010}

In this section, we will show a case study to illustrate our methods.

\subsection{A synoptic scale perspective}

We have chosen the winter storm "Xynthia", which caused severe storm surges and flooding in Western Europe in February 2010 (Liberato et al., 2013). This long-lived cyclone originated in the subtropical North Atlantic near $55^{\circ} \mathrm{W}$, intensified rapidly and reached the French Atlantic coast with a core pressure of about $970 \mathrm{hPa}$ at 00:00 UTC 28 February (Fig. 1). The cyclone then moved to the Baltic Sea, weakened, became stationary and persisted until 8 March. The situation at 06:00 UTC 26 February 2010 is shown in Fig. 2. 


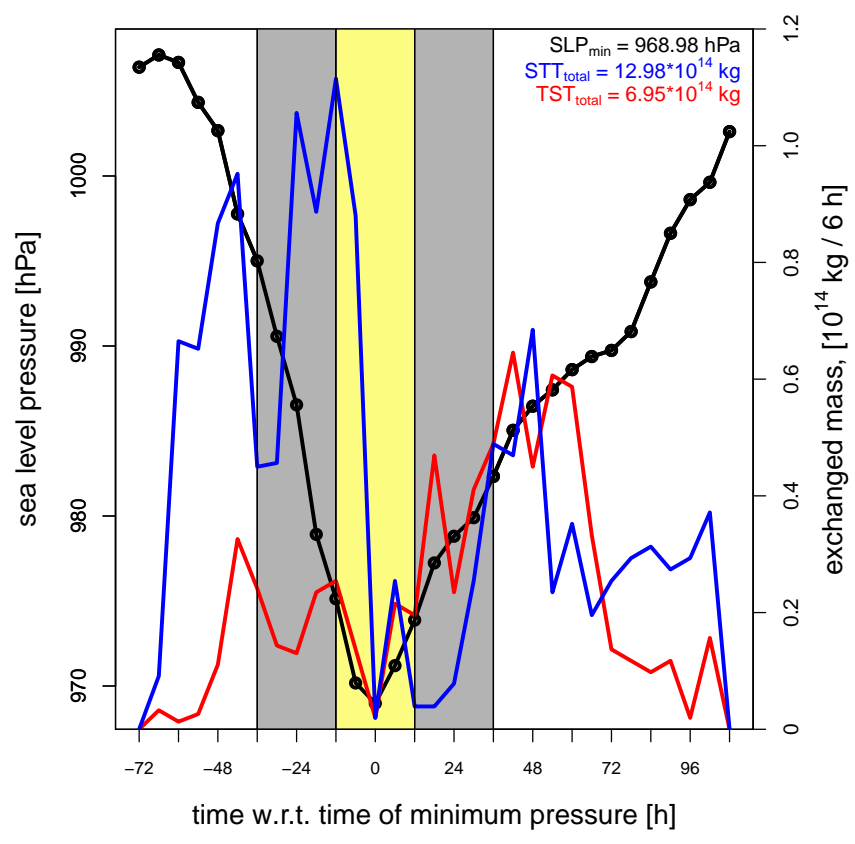

Figure 1. Time series of SLP (hPa) in black and the exchanged mass $\left(10^{14} \mathrm{~kg}\right)$ of STT (blue) and TST (red) as a function of time (h) with respect to the time of minimum SLP of cyclone "Xynthia". $0 \mathrm{~h}$ corresponds with 00:00 UTC of 28 February 2010. The grey boxes correspond to the deepening and decaying phase of the cyclone, respectively, and the yellow box indicates the mature phase. The separation into phases is later used for the analysis in Sect. 4.3 (see also Figs. 9 and 10).

A large number of STT events occur right at the cyclone centre (near $30^{\circ} \mathrm{W} / 30^{\circ} \mathrm{N}$, central pressure $998 \mathrm{hPa}$ ). A vertical cross-section along $30^{\circ} \mathrm{W}$ from 15 to $45^{\circ} \mathrm{N}$ is shown in Fig. 3. The strong baroclinic zone to the north of the cyclone is not associated with a tropopause fold. A closer analysis (not shown) reveals that most of these STT events can be associated with material PV destruction above a local latent heating maximum due to in-cloud freezing. Note also the STE events associated with the subtropical jet stream over North Africa shown in Fig. 2. At 00:00 UTC 27 January 2010, Xynthia moved north-eastward and significant STT occurred on its north-western side (Fig. 4) in a region with a rather low tropopause (reaching down to $400 \mathrm{hPa}$ ). Nearly all of these exchange events are associated with the cyclone by our method (gray area in Fig. 4). Figures 2 and 4 illustrate that our method is capable of taking into account exchange events that occur in the direct vicinity of the cyclone centre and/or in the upstream trough. Due to the limited maximum extension of the cyclone area (see Sect. 2.2), we obtain a trustworthy lower bound of STE attributed to cyclones.

\subsection{STE integrated along cyclone track}

Time series of SLP and exchanged mass for STT and TST events for cyclone "Xynthia" are presented in Fig. 1. This

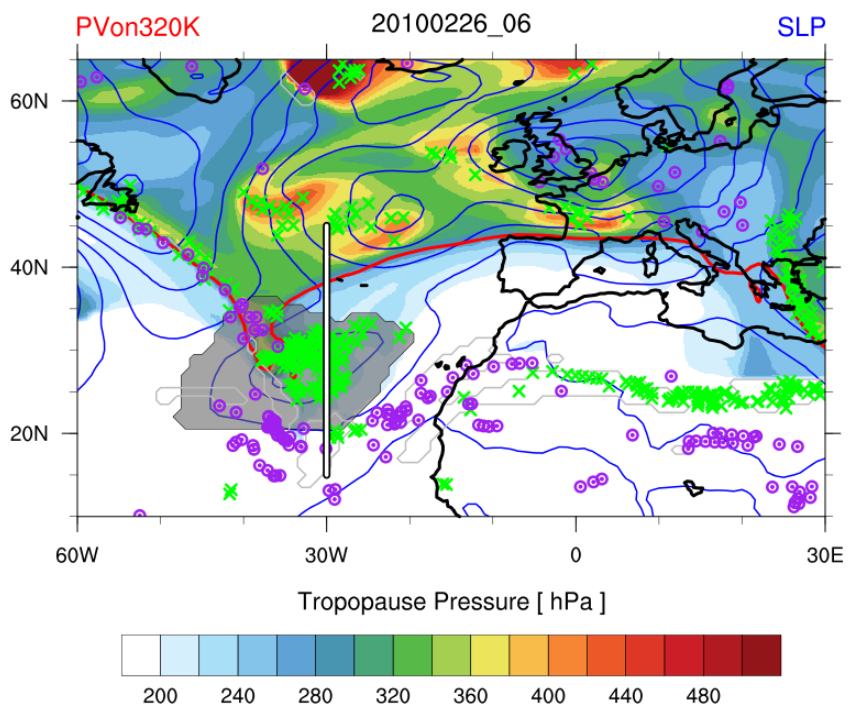

Figure 2. Pressure at the dynamical tropopause (in hPa, coloured), PV at $320 \mathrm{~K}$ (red line), and contours of SLP (blue, contour interval $5 \mathrm{hPa}$ ) at 06:00 UTC 26 February 2010. Cyclone Xynthia, as identified by our method, is shaded gray. STT and TST events occurring within a $6 \mathrm{~h}$ symmetric time window are depicted by green crosses and purple dotted circles, respectively. Gray contours indicate a folded tropopause (i.e., multiple vertical crossings)

shall illustrate the combination of the cyclone and STE data. The SLP shows the three different phases of the life cycle of a cyclone. During the intensification phase, the SLP is reduced rapidly by over $30 \mathrm{hPa}$ in $72 \mathrm{~h}$. In the mature phase the minimum SLP of $968.98 \mathrm{hPa}$ is reached, which defines the intensity of "Xynthia". The minimum SLP is reached $72 \mathrm{~h}$ after the first detection of the cyclone by the tracking algorithm. After the mature stage, SLP rises and the cyclone decays slowly. "Xynthia" is last found by the tracking algorithm after $180 \mathrm{~h}$ of overall lifetime, which is exceptionally long for a North Atlantic cyclone. The mean lifetime of all cyclones used in the present study is $79.4 \mathrm{~h}$, the median is $66 \mathrm{~h}$, and the maximum $390 \mathrm{~h}$. The grey boxes in Fig. 1 indicate the intensification ( -36 to $-12 \mathrm{~h}$ prior to the time of minimum SLP) and the decaying phase (12 to $36 \mathrm{~h}$ after the time of minimum SLP), respectively. Note, to have comparable time windows for all cyclones, regardless of their lifetime, the intensification and decaying phases are limited to $24 \mathrm{~h}$. The mature phase of the cyclone is defined as the time window $12 \mathrm{~h}$ before and after the time the minimum is reached and is indicated by the yellow box in Fig. 1 .

The exchanged masses of STT and TST for each 6 hourly time step are shown as blue and red lines in Fig. 1, respectively. In the beginning of the lifecycle, no STE events are found in the vicinity of "Xynthia". STT is dominant during the intensification and mature phase of the cyclone, while TST becomes more important in the long decaying phase of "Xynthia". In the end, the total exchanged mass for STT accounts to $12.98 \times 10^{14} \mathrm{~kg}$ and for TST to $6.95 \times 10^{14} \mathrm{~kg}$. 


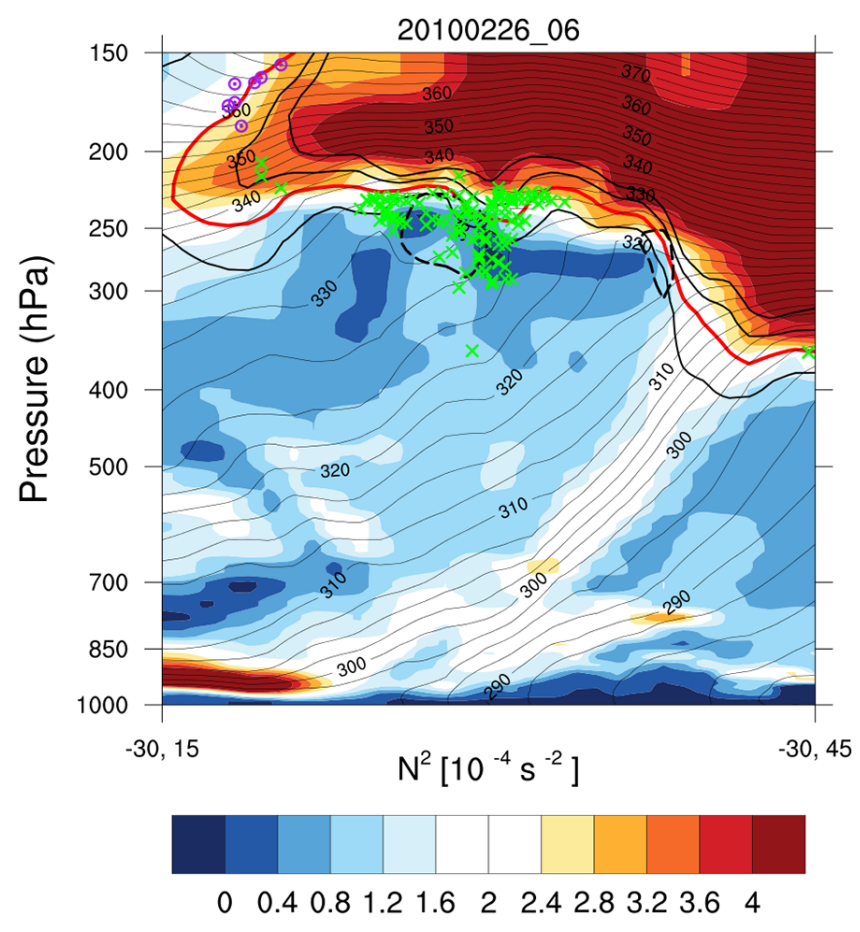

Figure 3. Vertical cross-section along $30^{\circ} \mathrm{W}$ from 15 to $45^{\circ} \mathrm{N}$ (white line in Fig. 2) at 06:00 UTC 26 February 2010. The Brunt-Väisälä frequency $N^{2}$ is shown with coloured contours (in $10^{-4} \mathrm{~s}^{-2}$ ), the thin black lines show isentropes (in $\mathrm{K}$ ) and the thick contours are isosurfaces of PV (1-4 pvu, 2 pvu red, rest black). STT and TST events occurring in a symmetric $6 \mathrm{~h}$ time window and within $\pm 5^{\circ}$ longitude are shown with green crosses and purple dotted circles, respectively.

This above mentioned method is now applied to all North Atlantic cyclones from 1979 to 2011 and the results are presented in the following.

\section{Climatology}

\subsection{Fraction of STE associated with cyclones}

The seasonally averaged mass fluxes of STT and TST in the North Atlantic are shown in Figs. 5 and 6, respectively. The white contours indicate the percentage of the total mass flux that is due to exchange events associated with cyclones. The highest relative fraction (around $60 \%$ ) is found for STT south of Newfoundland in winter (DJF). In spring (MAM) and fall (SON), around $50 \%$ of the total STT flux is associated with cyclones in this region while in summer (JJA), this value drops to $40 \%$. During this time the maximum of $50 \%$ is found west of Great Britain and Ireland. The values for TST are in the same order, except for summer, when over $50 \%$ of the total TST flux is associated with cyclones over the Hudson Bay and eastern parts of Canada. Note that the percentage values are large where the cyclones typically

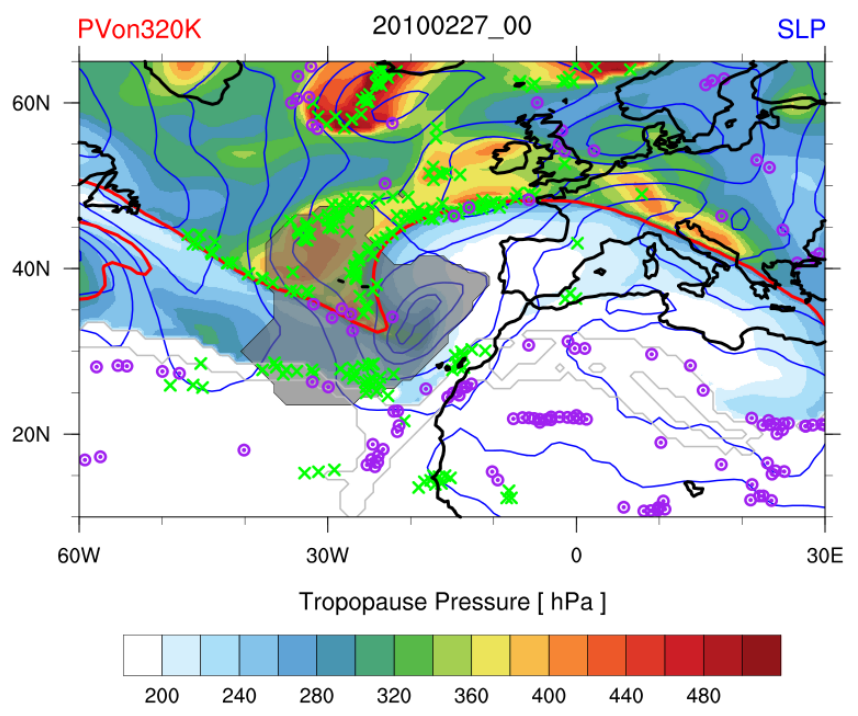

Figure 4. As Fig. 2 but at 00:00 UTC 27 February 2010.

become mature, large and stationary (e.g., central North Atlantic).

\subsection{Influence of cyclone intensity}

In this section, we investigate the climatological relationship between STE in the vicinity of North Atlantic cyclones and their intensity. The intensity of a cyclone is defined as the minimum SLP of the cyclone during its lifecycle. All cyclones in the period investigated in this study (1979-2011) are grouped into bins with a width of $5 \mathrm{hPa}$, ranging from 930 to $1035 \mathrm{hPa}$. In Fig. 7, the dependency of the exchanged mass per cyclone on the cyclone intensity is shown using box-and-whisker plots for STT and TST in winter (DJF) and summer (JJA). The median of each pressure bin is given by the bold black line, $50 \%$ of the data are within the box and the whiskers (dashed lines) denote the 1.5 interquartile range. The statistical outliers are marked as circles.

For winter and summer and for both directions (STT and TST) a clear dependency of the exchanged mass on the minimum SLP of the cyclone can be seen. With decreasing minimum SLP, more mass is exchanged between stratosphere and troposphere along the cyclone track. In winter (DJF) more mass is exchanged for STT than for TST, especially for cyclones with higher intensities, i.e., lower minimum SLP. The STE values integrated along the track of cyclone "Xynthia" (core pressure of $969 \mathrm{hPa}$ ), portrayed previously in Fig. 1, are extremely high for STT $\left(1.30 \times 10^{15} \mathrm{~kg}\right)$ compared to the statistical distribution shown in Fig. 7 (top left) and also very high for TST $\left(0.70 \times 10^{15} \mathrm{~kg}\right)$.

During the summer months (JJA) the exchanged mass for STT and TST is very similar. Additionally, the dependency of the exchanged mass on the minimum SLP is stronger, i.e., the pathway of the median values is steeper with decreasing 


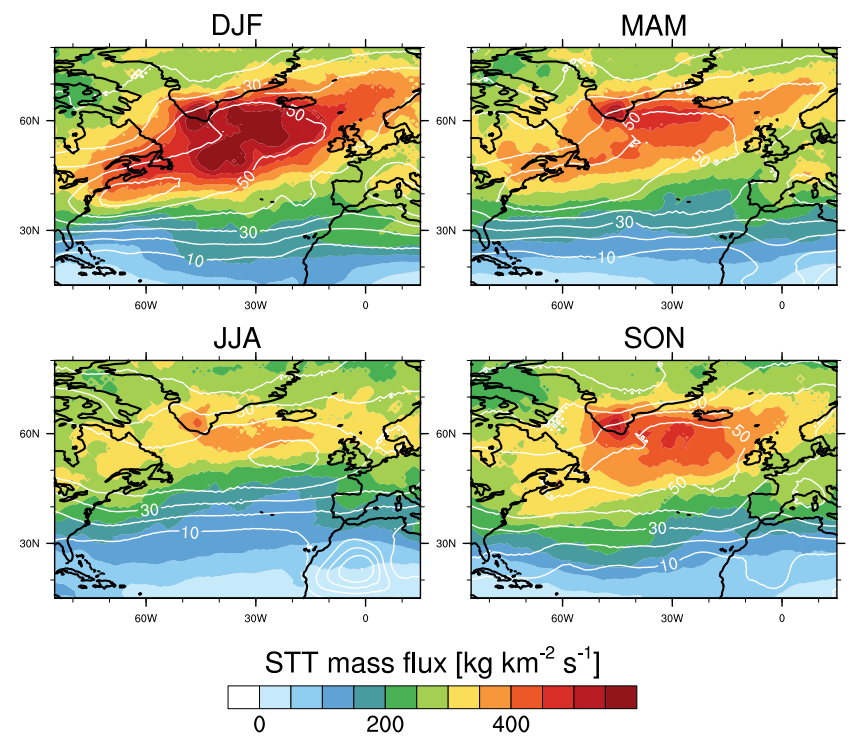

Figure 5. Seasonally averaged STT mass flux $\left(\mathrm{kg} \mathrm{m}^{-2} \mathrm{~s}^{-1}\right)$ for 1979-2011. The white contours indicate the fraction of the mass flux that is associated with cyclones (in \%, contour interval 10\%).

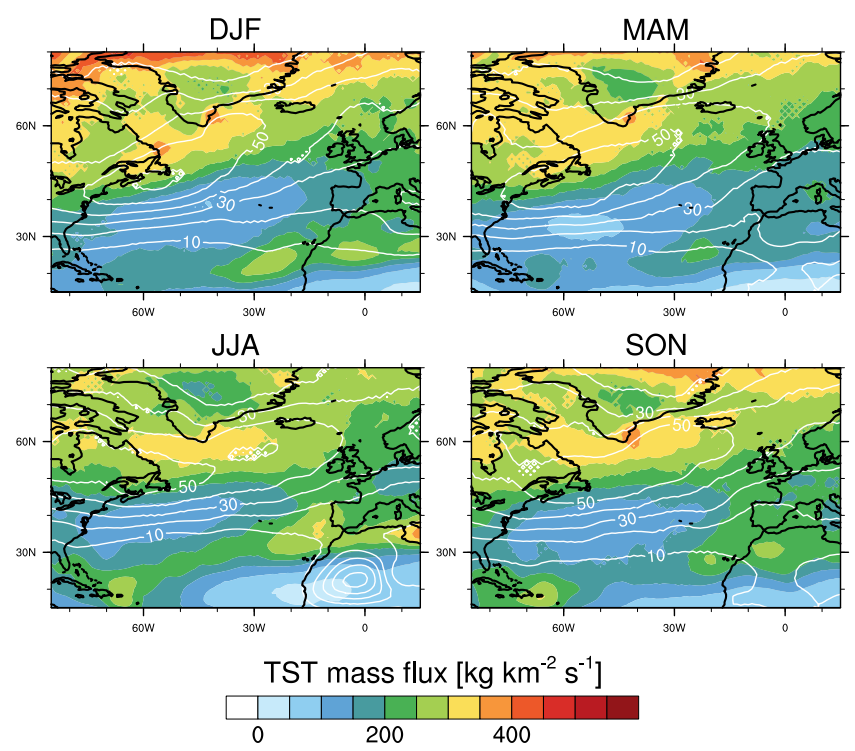

Figure 6. As Fig. 5 but for TST instead of STT.

minimum SLP compared to the winter months. However, no cyclones with minimum SLP of less than $960 \mathrm{hPa}$ are found.

In Table 1, the total exchanged mass for STT and TST along cyclone tracks and for the complete North Atlantic are listed for all seasons. As an average over all seasons, $34 \%$ more mass is exchanged near North Atlantic cyclones for STT than for TST. Averaged over the entire region $60 \%$ of the total STT is associated with cyclones and $49 \%$ of TST, and these values have only little seasonal variation. Next, the possibility that the increase of exchanged mass for more intense cyclones (see Fig. 7) is solely due to a longer life time
Table 1. Total mass $\left(10^{17} \mathrm{~kg}\right)$ per season from 1979 to 2011 for STT and TST in the vicinity of cyclones over the North Atlantic and the total mass over the entire North Atlantic as well as the ratio between STT and TST. The minimum lifetime of a cyclone is 1 day.

\begin{tabular}{lrcc|ccc}
\hline & \multicolumn{3}{c|}{ near cyclones } & \multicolumn{3}{c}{ North Atlantic } \\
\cline { 2 - 7 } Seasons & STT & TST & STT/TST & STT & TST & STT/TST \\
\hline DJF & 13.3 & 8.4 & 1.58 & 22.0 & 17.8 & 1.24 \\
MAM & 11.2 & 8.1 & 1.38 & 18.5 & 16.2 & 1.14 \\
JJA & 8.9 & 8.1 & 1.10 & 15.0 & 16.4 & 0.91 \\
SON & 11.3 & 8.8 & 1.28 & 19.1 & 17.6 & 1.09 \\
\hline TOTAL & 44.7 & 33.4 & 1.34 & 74.6 & 68.0 & 1.10 \\
\hline
\end{tabular}

Table 2. Average mass flux $\left(\mathrm{kg} \mathrm{km}^{-2} \mathrm{~s}^{-1}\right)$ per season from 1979 to 2011 for STT and TST in the vicinity of cyclones over the North Atlantic and the average over the entire North Atlantic as well as the ratio between STT and TST. The minimum lifetime of a cyclone is 1 day.

\begin{tabular}{lccc|ccc}
\hline & \multicolumn{3}{c|}{ near cyclones } & \multicolumn{3}{c}{ North Atlantic } \\
\cline { 2 - 7 } Seasons & STT & TST & STT/TST & STT & TST & STT/TST \\
\hline DJF & 421.9 & 271.0 & 1.56 & 311.0 & 252.0 & 1.23 \\
MAM & 342.8 & 243.7 & 1.41 & 262.1 & 229.0 & 1.14 \\
JJA & 254.4 & 230.9 & 1.10 & 212.8 & 231.9 & 0.92 \\
SON & 344.0 & 271.3 & 1.27 & 271.0 & 248.8 & 1.09 \\
\hline MEAN & 340.7 & 254.2 & 1.34 & 264.2 & 240.4 & 1.10 \\
\hline
\end{tabular}

has to be excluded. Therefore, in a next step, the exchanged mass is weighted with the size and the life time of each cyclone to determine the mass flux in the vicinity of a cyclone as a function of its minimum SLP. Figure 8 shows the mass flux per cyclone depending on its minimum SLP. Similar to the total exchanged mass, the mass flux also shows an increase with decreasing minimum SLP of a cyclone. Nevertheless, there are some important differences. The increase of mass flux is not as steep compared to the exchanged mass, because the lifetime and the size of the cyclones are taken into account. Overall, the results show a higher variability which does not strongly depend on the minimum SLP. Note that the variability is clearly higher during winter than during summer. Additionally, the number of outliers (marked by circles) is significantly higher in winter due to very small or very short-lived cyclones. During winter, the mass flux is definitely higher for STT than for TST.

Table 2 lists the average mass flux for STT and TST in all seasons. The results show the same characteristics as the exchanged mass (see Table 1) with the highest fluxes in winter for STT. Additionally, winter shows the greatest discrepancy between STT and TST, where the STT flux is $56 \%$ larger than the TST flux. In summer the STT flux is lowest for all seasons. Overall, the yearly average of the mass flux in the vicinity of a North Atlantic cyclone is 
DJF STT

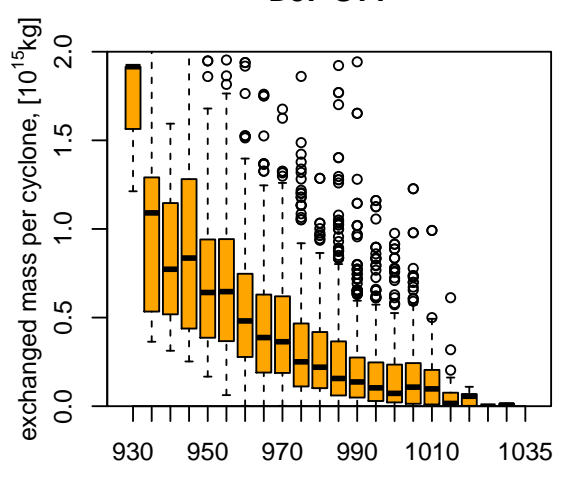

Minimum pressure of a cyclone, $[\mathrm{hPa}]$

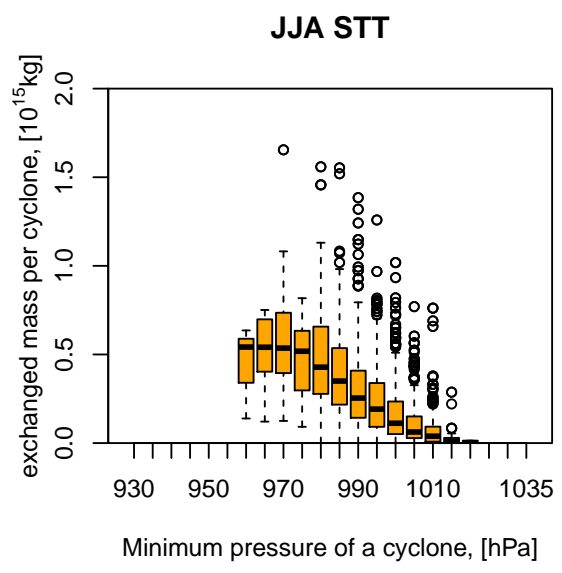

DJF TST

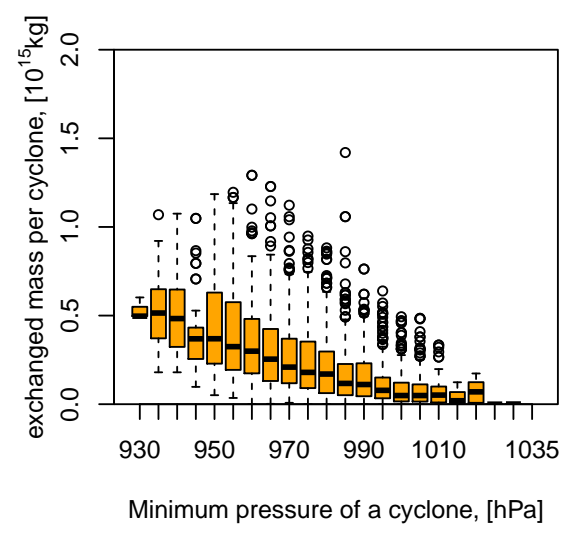

JJA TST

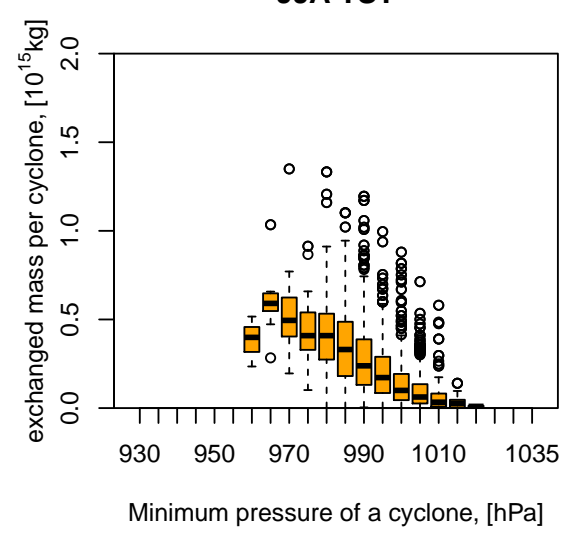

Figure 7. Box-and-Whisker plot showing the dependency of the total exchanged mass per cyclone $\left(10^{15} \mathrm{~kg}\right)$ for STT (left column) and TST (right column) on the minimum SLP of a cyclone (hPa) over the North Atlantic during DJF (upper row) and JJA (lower row).

340.7 and $254.2 \mathrm{~kg} \mathrm{~km}^{-2} \mathrm{~s}^{-1}$ for STT and TST, respectively. Comparing these results to the average mass flux across the tropopause in the entire Northern Hemisphere (approximately $175 \mathrm{~kg} \mathrm{~km}^{-2} \mathrm{~s}^{-1}$ ) allows to conclude that the mass flux in the vicinity of North Atlantic cyclones is significantly higher compared to cyclone-free regions.

\subsection{Position of STE relative to cyclone centre}

In addition to a quantitative attribution of STE to cyclones, it is also of interest to study where STE takes place relative to the cyclone centre, i.e., to assess whether there are distinct patterns discernible or if STE is randomly distributed around the centre. To address this question, composites of STE are compiled (Figs. 9 and 10). Our method works as follows: every extra-tropical cyclone is placed in the centre of a rotated longitude/latitude grid and the coordinates of all STE events attributed to this cyclone are then transformed accordingly. Thus, the locations of the STE events are shown relative to the cyclone centre. This is repeated for all cyclones and associated STE events in the climatology, resulting in an STE density around the cyclone centres. Note that the coordinate transformation, placing the cyclone centre at the intersection of the rotated $0^{\circ}$ meridian and equator, guarantees that all cyclones and exchange events are treated equivalently. No distortion due to the converging meridians toward the poles occurs and the spacing of $1^{\circ}$ in the rotated grid corresponds to $\sim 110 \mathrm{~km}$ in good approximation. Hence, the domain shown in Figs. 9 and 10 covers an area of approximately $2000 \mathrm{~km} \times 2000 \mathrm{~km}$ around the cyclone centre.

In addition to STE composites relative to the cyclone centre, Figs. 9 and 10 also include composites of the cyclone mask (see Sect. 2) and of PV at the $315 \mathrm{~K}$ isentrope. The former gives a good idea of the horizontal extension of the cyclones included in the composite; the latter shows the upper-level dynamical evolution of the PV field and is hence a proxy of the upper-level structure. At the same time, by definition, this field also shows the mean position of the dynamical tropopause at this isentropic level. Finally, note that in Figs. 9 and 10, only cyclones in the North Atlantic region which deepen by at least $10 \mathrm{hPa}$ during their lifetime are considered (see Sect. 2). The results are presented for the (i) intensification phase, (ii) mature phase, and (iii) decaying 
Northern Atlantic

DJF STT

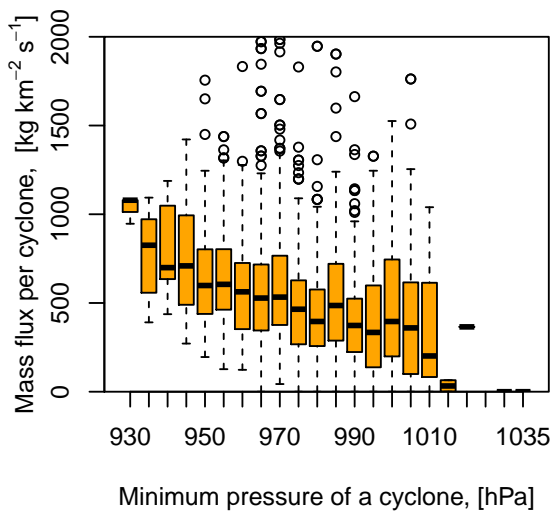

JJA STT

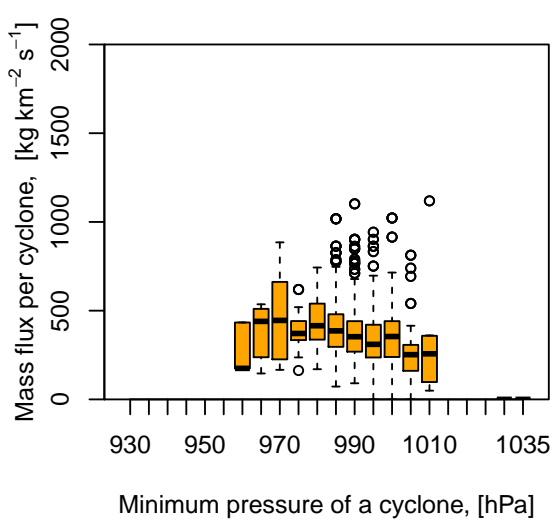

Figure 8. As Fig. 7 but for mass flux $\left(\mathrm{kg} \mathrm{km}^{-2} \mathrm{~s}^{-1}\right)$.

phase. Additionally, for each phase of the life cycle the mass flux for STT and TST is shown.

With respect to STT (Fig. 9, second row) several distinct features are discernible: (i) during the intensification phase (left), most STT takes place in a sector south-west of the cyclone centre. The maximum is found well within the mean cyclone mask and resembles a rectangle of nearly $400 \mathrm{~km} \times 300 \mathrm{~km}$ width. In this intensification phase, the PV contours also indicate a clear structure, where the highest PV values are reminiscent of a stratospheric PV trough to the north-west of the cyclone centre. (ii) During the mature phase (Fig. 9, middle column), the pattern changes: the STT maximum is shifted further to the south and significant STT can now also be found to the south-east of the cyclone centre. The shift in the STT pattern goes along with a clear evolution of $\mathrm{PV}$ at $315 \mathrm{~K}$. In fact, the PV signal is indicative for cyclonic rolling-up of the upper-level PV trough. (iii) This evolution becomes most pronounced in the decaying phase (right column). Here, the averaged upper-level PV has formed a distinct, nearly axisymmetric PV cutoff situated exactly over the cyclone centre. The distribution of STT becomes much more symmetric, and is also located near the cyclone centre.

The magnitude of the exchanged STT mass (Fig. 9, first row) is also changing with time. The dependency of the mass on the minimum SLP (based on the complete life cycle) is visible for all life cycle stages. However, the lowest exchanged mass can be found during the intensification phase. The exchanged STT mass is highest when the cyclones reach their minimum SLP. This is the time when the geographical distribution of the STT events shows the largest asymmetry. Here, most of the STT mass exchange occurs south of the cyclone centre, where the highest wind speeds of Northern Hemisphere extratropical cyclones are expected (Catto et al., 2010, Fig. 8). In the decaying phase the exchanged mass is reduced, but slightly higher compared to the intensification phase.

A similar analysis can be repeated with respect to TST (Fig. 10, second row). Again the same time windows of the cyclones' lifetimes are considered (from left to right) and the same cyclones are included in the composites. Compared to the STT pattern, the TST pattern is much more spatially con- 

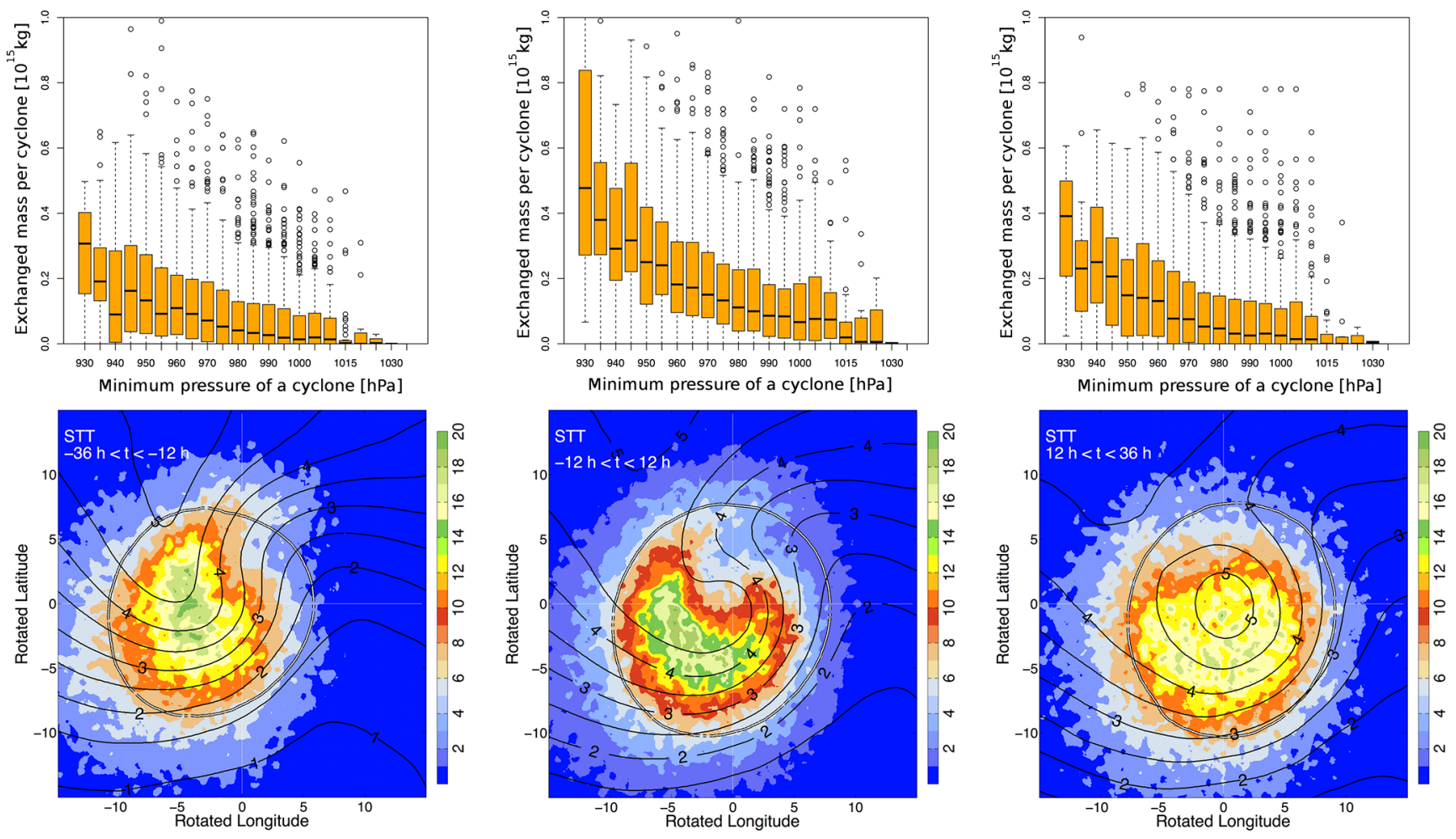

Figure 9. Box-and-Whisker plots for exchanged mass of STT (first row) and PV- and exchange composites relative to cyclone centre for STT (second row) for the winter months (DJF). Black lines denote PV at $315 \mathrm{~K}$, colouring shows the density of exchange events, the grey line shows the mean extension of a cyclone. The left column shows the result for the intensification phase, the middle column for the mature phase and the right column for the decaying phase. The values for the mean STT flux per cyclone must be multiplied by 245 to get the flux in $\mathrm{kg} \mathrm{km}^{-2} \mathrm{~s}^{-1}$. Note, all STE events within a $6 \mathrm{~h}$ time window centred around the cyclone time are taken into account.

fined and axisymmetrically distributed around the cyclone centre. Especially in the intensification and mature phase, the TST decays rapidly for distances larger than $\approx 250 \mathrm{~km}$ away from the centre. There is a slight indication of a small geographical shift toward the south-east from the intensification to the mature phase, most likely associated with the corresponding evolution of the upper-level PV signal. Indeed, in the intensification phase the highest number of TST events is found in a narrow region on the downstream side of the PV trough; at minimum SLP, however, the peak TST is found right below the rolling-up PV trough. During the decaying phase (right) the horizontal extension of the TST widens and is slightly shifted to the south-west of the cyclone centre, nearly perfectly aligned with the upper-level PV signal.

The exchanged TST mass is shown in Fig. 10 (first row). The evolution of the exchanged mass between the different lifecycle phases shows a similar behaviour compared to STT. Although the absolute numbers are smaller for TST, the relative differences are comparable. Figure 11 shows the differences between the lifecycle phases for winter cyclones as a function of cyclone intensity. The quantity shown is the ratio between the median value of the exchanged STT (TST) mass of the intensification and mature phases (left) and decaying and mature phases (right). A value of 0.5 means that during the intensification (decaying) phase the exchanged mass corresponds to $50 \%$ of the mass exchanged during the mature phase. The curves are very similar for STT and TST and show a clear dependency on the cyclones' minimum SLP. While weak cyclones exchange most mass during the mature phase, more intense cyclones exchange proportionally more mass also during the intensification and decay. This implies that the processes responsible for STE are working more effectively over a longer time period for intense rather than for weak cyclones.

\section{Conclusions, discussion and outlook}

In this study we investigated stratosphere-troposphere exchange in the vicinity of extratropical cyclones over the North Atlantic. A chain of sophisticated tools and methods based on ERA-Interim data enabled us to obtain a detailed attribution of individual STE events to a particular cyclone track in the extratropical North Atlantic from 1979 to 2011. A case study of a winter cyclone was presented to illustrate the methods and conceptual approach. The results of the cli- 

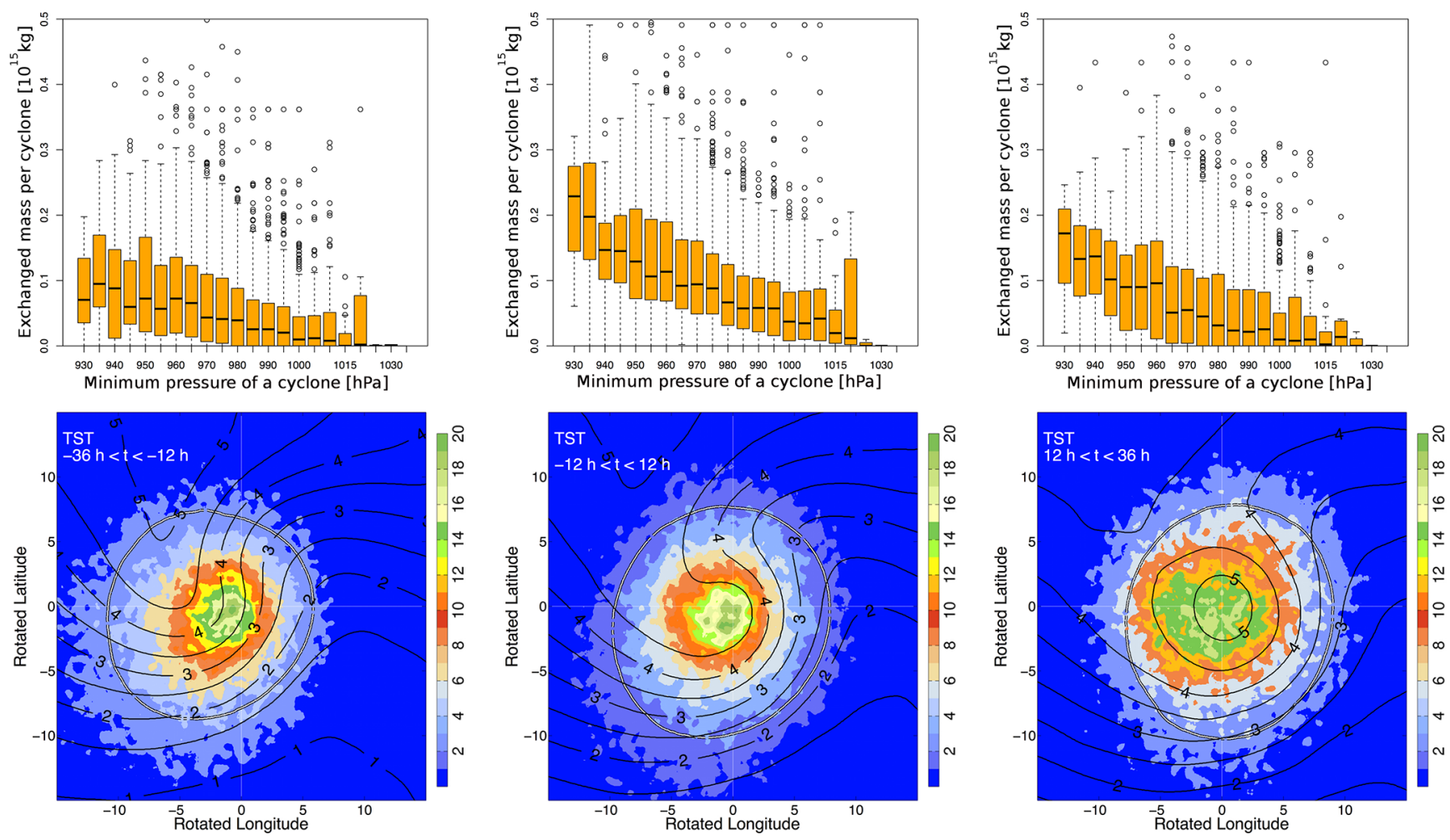

Figure 10. As Fig. 9 but for TST instead of STT.
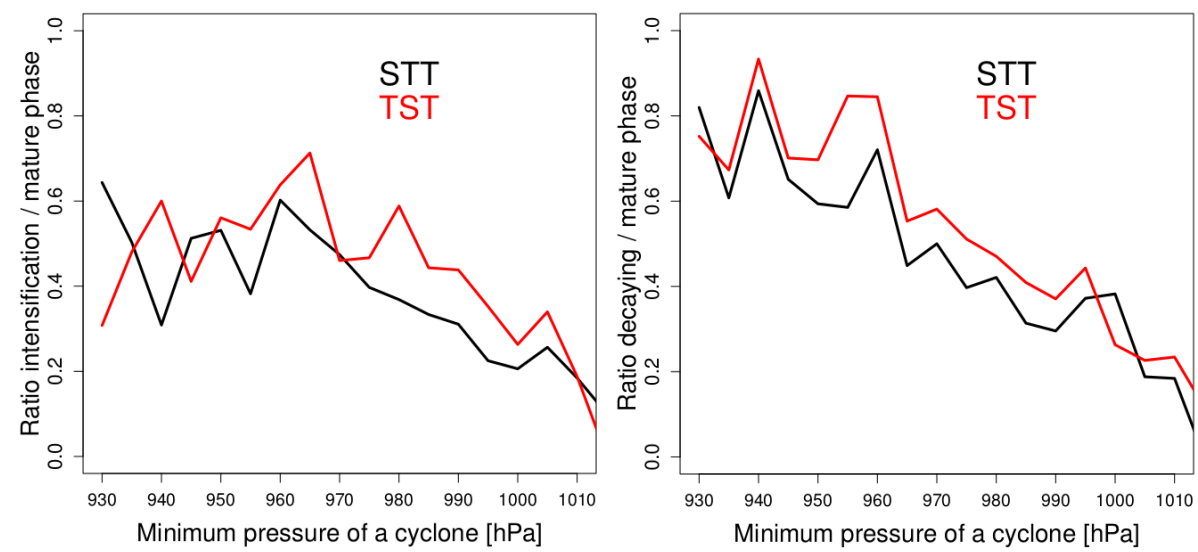

Figure 11. Ratio between the exchanged mass during the intensification and the mature phase (left) and between the decaying and mature phase (right) for STT (black) and TST (red) as a function of the cyclone's minimum SLP (only for winter). The ratio is calculated using the median from the box and whisker plots of Figs. 9 and 10. Note, results are presented here up to $1010 \mathrm{hPa}$ due to the low number of cyclones for higher minimum SLP.

matological investigations are summarized and discussed in the following.

\subsection{Main results}

\subsubsection{Fraction of STE associated with cyclones}

As indicated by earlier case studies summarized in the introduction, STE is typically enhanced in the vicinity of ex- tratropical cyclones. STE in cyclones therefore contributes significantly to total STE and this has been quantified for the first time in this study for the North Atlantic storm track. The highest fraction of STE associated with cyclones compared to all STE events over the North Atlantic can be found during winter, when up to $60 \%$ of the STT mass flux occurs near cyclones. In spring and fall, this value drops to around $50 \%$. The lowest fraction can be found during summer, when 
over a large area less than $50 \%$ of the STT mass flux can be attributed to cyclones. The values for the TST mass flux are spatially similarly distributed but slightly higher than for STT during summer.

\subsubsection{Influence of cyclone intensity on STE}

The exchanged mass across the tropopause in the vicinity of a cyclone is strongly dependent on the cyclone intensity, expressed as the minimum SLP during its lifecycle. With increasing cyclone intensity (i.e., lower minimum SLP), the spatially and temporally integrated STT and TST mass fluxes along the cyclone tracks are enhanced. In winter, the dependency is stronger for STT than for TST. During summer, both directions of exchange have a comparable dependency on the intensity.

When considering the averaged mass flux along a cyclone track, i.e., dividing the integrated exchange values by the size and lifetime of the cyclone, the results show the same overall behaviour. However, the variability of the data within the intensity classes is increasing due to the variability of size and lifetime of North Atlantic cyclones. On average, the STT mass flux for a cyclone with a minimum SLP of $1000 \mathrm{hPa}$ in winter (summer) is approximately $404 \mathrm{~kg} \mathrm{~km}^{-2} \mathrm{~s}^{-1}\left(252 \mathrm{~kg} \mathrm{~km}^{-2} \mathrm{~s}^{-1}\right)$, and for a cyclone with a minimum SLP of $965 \mathrm{hPa}$ the corresponding average flux amounts to $527 \mathrm{~kg} \mathrm{~km}^{-2} \mathrm{~s}^{-1}$ $\left(439 \mathrm{~kg} \mathrm{~km}^{-2} \mathrm{~s}^{-1}\right)$. The TST mass flux for a winter (summer) cyclone with a minimum core pressure of $1000 \mathrm{hPa}$ is about $166 \mathrm{~kg} \mathrm{~km}^{-2} \mathrm{~s}^{-1}\left(219 \mathrm{~kg} \mathrm{~km}^{-2} \mathrm{~s}^{-1}\right)$, and for a cyclone with a minimum core pressure of $965 \mathrm{hPa}$ about $338 \mathrm{~kg} \mathrm{~km}^{-2} \mathrm{~s}^{-1}$ $\left(413 \mathrm{~kg} \mathrm{~km}^{-2} \mathrm{~s}^{-1}\right)$. Note that the dependency of the averaged mass flux on the cyclone intensity is weaker compared to the integrated exchanged mass. The reason for the dependency of the exchanged mass (or mass flux) on the intensity of cyclones is difficult to unravel from a climatological study alone. One hypothesis is that the increase in exchanged mass with increasing cyclone intensity is associated with enhanced diabatic processes, in particular latent heat release in clouds, and potentially also the infrared cooling at cloud top level. Climatological studies on cyclone intensification (e.g., Čampa and Wernli, 2012) clearly showed that latent heating is enhanced in strongly intensifying cyclones. This is corroborated by climatological studies of rainfall in extratropical cyclones, which show an increase of surface precipitation for more intense cyclones (Field and Wood, 2007). Since process studies (e.g., Lamarque and Hess, 1994, and others discussed in the introduction) highlighted the importance of the diabatic PV modification for STE, it is very likely that the same diabatic processes leading to cyclone intensification also increase the cross-tropopause mass exchange. In addition, the tropopause near intense cyclones is typically very low (Čampa and Wernli, 2012) and often forms filaments reaching deep into the troposphere. It is conceivable that the strong vertical wind shear in these regions results in more turbulence and hence more exchange.

\subsubsection{Position of STE relative to cyclone centre}

Composites of STE exchange locations relative to the cyclone centre were obtained to assess differences in the spatial distribution of STT and TST events. In the intensification phase most STT occurs south-west of the cyclone centre. This pattern moves to the south of the cyclone centre when the cyclone reaches its maximum intensity (minimum SLP). In the decaying phase the STT pattern becomes much more axisymmetric and is located right above the cyclone centre. It is notable that the pattern of STT goes along with the PV anomaly at $315 \mathrm{~K}$ indicating a cyclonic roll-up of the upper-level PV trough. In contrast, the TST pattern is much more spatially confined and axisymmetric. In the intensification phase the TST pattern is centred slightly downstream of the upper-level trough. However, during the mature phase of the cyclone the maximum of the TST pattern is aligned below the rolling-up PV trough. In the decaying phase the pattern of TST widens and is located south-west of the cyclone centre.

\subsubsection{STE with respect to the evolution of a cyclone}

The timing of STE with respect to the cyclone lifecycle shows some differences for STT and TST. Both show the highest amount of exchanged mass during the time of the cyclones maximum intensity. However, the median mass flux for STT at that time is clearly higher. The relative variability between the lifecycle phases is very similar for STT and TST. It is notable that the variability between the three phases also shows a clear dependency on the cyclones' minimum SLP. STE occurs in all phases for intense cyclones, but virtually only during the mature phase for weak cyclones; leading to the assumption that the duration of the processes responsible for the mass exchange act longer for intense rather than for weak cyclones.

\subsection{Caveats}

Several caveats concerning the data set and the methods are discussed in the following.

\subsubsection{STE in ERA-Interim data set}

The calculation of STE due to sub-grid-scale convective processes, which could be of importance in the vicinity of cyclones, is not possible using kinematic trajectories based on resolved wind fields in ERA-Interim reanalysis data. Therefore, the mass flux across the tropopause is probably underestimated. However, a quantification of this underestimation cannot be given using the presented method. For further information see also Škerlak et al. (2014) and references therein. 


\subsubsection{Cyclone size and tracking}

The size of the cyclone determines how many STE events are associated with it. Therefore, different definitions of the size will lead to different quantifications of the cross-tropopause transport assigned to a cyclone. While the definition of a cyclone affects its size, the identification of the cyclone track affects the lifetime and adds an uncertainty into the quantitative results of the exchanged mass (mass flux) per cyclone. An intercomparison of 15 different detection and tracking tools for extratropical cyclones (Neu et al., 2013) revealed that uncertainties are most notable for weak cyclones. However, the methods agreed well for cyclones in oceanic regions and also reproduced similar geographical patterns of cyclone frequency. Using a different method might therefore change the quantitative results of the investigation, but not the overall conclusion that there is a strong dependency of the STE flux on cyclone intensity.

\subsection{STE in future climate}

This investigation showed that cyclones play a very important role for extratropical STE. It was found that the exchanged mass (and mass flux) strongly depend on the intensity of a cyclone. It was also found that the preferred locations for STT and TST relative to the cyclone centre as well as their intensity vary between different stages of the cyclone's life cycle.

To make a statement on STE in the vicinity of cyclones for a future climate, projections of storm track activity under global warming can be used. Chang et al. (2012) examined storm track changes in the future climate using multi-model ensembles from the Coupled Model Intercomparison Project (CMIP5, Taylor et al., 2012) and found no systematic shift of Northern Hemisphere (NH) storm tracks during the $\mathrm{NH}$ winter and only a slight poleward shift during $\mathrm{NH}$ summer. Additionally, they found that the cyclone frequency is projected to be smaller over Europe and North America. Also, they noticed that the intensity of the cyclones is slightly decreased. This would lead to an overall decrease in exchanged mass across the tropopause in the vicinity of cyclones, when our results are taken into account. However, it has to be noted that Chang et al. (2012) found that the models generally simulate storm tracks that are too weak. Our results imply that a small deviation in the intensity of a cyclone can lead to a significant under- or overestimation of the STE mass flux. Hence, this implies that models have to be accurate in their description of the processes governing the life cycle of cyclones in order to project STE in the vicinity of cyclones, and therefore STE in general, properly.

\subsection{Outlook}

One way for future studies to gain more insight into the dependency of STE on cyclone intensity is a systematic and de- tailed climatological evaluation of the processes involved in STE near cyclones with different intensities to test the abovementioned hypothesis concerning the importance of diabatic processes. One approach could be to retrieve physical tendencies along trajectories within cyclones in order to investigate the influence of diabatic processes depending on cyclone intensity, which could be done from a climatological point of view. Another possibility is to conduct case studies of cyclones with various intensities in order to trace the PV rates of different diabatic processes within the cyclones. Additionally, it would also be worth looking into cases, where cyclones with very different intensities are associated with a similar mass flux (amount of exchanged mass) or, vice versa, cases, where cyclones with similar intensity end up in very different mass fluxes (amount of exchanged mass).

Acknowledgements. We thank MeteoSwiss and the ECMWF for granting access to the ERA-Interim data set and the two anonymous referees for their constructive critique of the former version of this paper. P. Reutter thanks P. Spichtinger for helpful discussions.

Edited by: G. Vaughan

\section{References}

Arnold, F., Schneider, J., Gollinger, K., Schlager, H., Schulte, P., Hagen, D. E., Whitefield, P. D., and van Velthoven, P.: Observation of upper tropospheric sulfur dioxide- and acetone-pollution: potenitial implications for hydroxyl radical aerosol formation, Geophys. Res. Lett., 24, 57-60, 1997.

Bourqui, M. S.: Stratosphere-troposphere exchange from the Lagrangian perspective: a case study and method sensitivities, Atmos. Chem. Phys., 6, 2651-2670, doi:10.5194/acp-6-2651-2006, 2006.

Brioude, J., Cammas, J.-P., and Cooper, O. R.: Stratospheretroposphere exchange in a summertime extratropical low: analysis, Atmos. Chem. Phys., 6, 2337-2353, doi:10.5194/acp-62337-2006, 2006.

Bush, A. B. G. and Peltier, W. R.: Tropopause folds and synopticscale baroclinic wave life cycles, J. Atmos. Sci., 51, 1581-1604, doi:10.1175/1520-0469(1994)051<1581:TFASSB > 2.0.CO;2, 1994.

Čampa, J. and Wernli, H.: A PV perspective on the vertical structure of mature midlatitude cyclones in the Northern Hemisphere., J. Atmos. Sci., 69, 725-740, 2012.

Catto, J. L., and Shaffrey, L. C., and Hodges, K. I.: Can climate models capture the structure of extratropical cyclones?, J. Climate, 23, 1621-1635, doi:10.1175/2009JCLI3318.1, 2010.

Chang, E. K. M., Guo, Y., and Xia, X.: CMIP5 multimodel ensemble projection of strom track change under global warming, J. Geophys. Res., 117, D23, doi:10.1029/2012JD018578, 2012.

Chen, B., Xu, X. D., Yang, S., and Zhao, T. L.: Climatological perspectives of air transport from atmospheric boundary layer to tropopause layer over Asian monsoon regions during boreal summer inferred from Lagrangian approach, Atmos. Chem. Phys., 12, 5827-5839, doi:10.5194/acp-12-5827-2012, 2012. 
Cooper, O. R., Moody, J. L., and Parrish, D. D.: Trace gas composition of midlatitude cyclones over the western North Atlantic Ocean: a seasonal comparison of $\mathrm{O}_{3}$ and CO, J. Geophys. Res., 107, D7, doi:10.1029/2001JD000902, 2002.

Danielsen, E. F.: Stratospheric-tropospheric exchange based on radioactivity, ozone and potential vorticity, J. Atmos. Sci., 25, 502-518, doi:10.1175/15200469(1968)025<0502:STEBOR>2.0.CO;2, 1968.

Dee, D. P., Uppala, S. M., Simmons, A. J., Berrisford, P., Poli, P., Kobayashi, S., Andrae, U., Balmaseda, M. A., Balsamo, G., Bauer, P., Bechtold, P., Beljaars, A. C. M., van de Berg, L., Bidlot, J., Bormann, N., Delsol, C., Dragani, R., Fuentes, M., Geer, A. J., Haimberger, L., Healy, S. B., Hersbach, H., Holm, E. V., Isaksen, L., Kallberg, P., Köhler, M., Matricardi, M., McNally, A. P., Monge-Sanz, B. M., Morcette, J.-J., Park, B.-K., Peubey, C., de Rosnay, P., Tavolato, C., Thepaut, J.-N., and Vitart, F.: The ERA-Interim reanalysis: configuration and performance of the data assimilation system, Q. J. Roy. Meteor. Soc., 137, 553-597, doi:10.1002/qj.828, 2011.

Ertel, H.: Ein neuer hydrodynamischer Wirbelsatz, Meteorol. Z., 59, 271-281, 1942.

Field, P. R. and Wood, R.: Precipitation and cloud structure in midlatitude cyclones, J. Climate, 20, 233-254, 2007.

Gray, S. L.: A case study of stratosphere to troposphere transport: the role of convective transport and the sensitivity to model resolution, J. Geophys. Res., 108, 4590, doi:10.1029/2002JD003317, 2003.

Holton, J. R., Haynes, P. H., McIntyre, M. E., Douglass, A. R., Rood, R. B., and Pfister, L.: Stratosphere-troposphere exchange, Rev. Geophys., 33, 403-440, doi:10.1029/95RG02097, 1995.

Hoskins, B. J., McIntyre, M. E., and Robertson, A. W.: On the use and significance of isentropic potential vorticity maps, Q. J. Roy. Meteor. Soc., 111, 877-946, doi:10.1002/qj.49711147002, 1985.

Johnson, W. B. and Viezee, W.: Stratospheric ozone in the lower troposphere - I. Presentation and interpretation of aircraft measurements, Atmos. Environ., 15, 1309-1323, doi:10.1016/00046981(81)90325-5, 1967.

Kowol-Santen, J., Elbern, H., and Ebel, A.: Estimation of crosstropopause airmass fluxes at midlatitudes: comparison of different numerical methods and meteorological situations, Mon. Weather Rev., 128, 4045-4057, 2000.

Krebsbach, M., Schiller, C., Brunner, D., Günther, G., Hegglin, M. I., Mottaghy, D., Riese, M., Spelten, N., and Wernli, H.: Seasonal cycles and variability of $\mathrm{O}_{3}$ and $\mathrm{H}_{2} \mathrm{O}$ in the UT/LMS during SPURT, Atmos. Chem. Phys., 6, 109-125, doi:10.5194/acp-6-109-2006, 2006.

Lamarque, J.-F. and Hess, P. G.: Cross-tropopause mass exchange and potential vorticity budget in a simulated tropopause folding, J. Atmos. Sci., 51, 2246-2246, doi:10.1175/15200469(1994)051<2246:CTMEAP>2.0.CO;2, 1994.

Lane, T. and Sharman, R.: Gravity wave breaking, secondary wave generation, and mixing above deep convection in a threedimensional cloud model, Geophys. Res. Lett., 33, L23813, doi:10.1029/2006GL027988, 2006.

Lefohn, A. S., Wernli, H., Shadwick, D., Limbach, S., Oltmans, S. J., and Shapiro, M.: The importance of stratospherictropospheric transport in affecting surface ozone concentrations in the western and northern tier of the United States, Atmos.
Environ., 45, 4845-4857, doi:10.1016/j.atmosenv.2011.06.014, 2011.

Liberato, M. L. R., Pinto, J. G., Trigo, R. M., Ludwig, P., Ordóñez, P., Yuen, D., and Trigo, I. F.: Explosive development of winter storm Xynthia over the subtropical North Atlantic Ocean, Nat. Hazards Earth Syst. Sci., 13, 2239-2251, doi:10.5194/nhess-13-2239-2013, 2013.

Lin, M., Fiore, A. M., Cooper, O. R., Horowitz, L. W., Langford, A. O., Levy, H., Johnson, B. J., Naik, V., Oltmans, S. J., and Senff, C. J.: Springtime high surface ozone events over the western United States: quantifying the role of stratospheric intrusions, J. Geophys. Res., 117, D00V22, doi:10.1029/2012JD018151, 2012.

Liu, C., Liu, Y., Liu, X., and Chance, K.: Dynamical and chemical features of a cutoff low over northeast China in July 2007: results from satellite measurements and reanalysis, Adv. Atmos. Sci., 30, 525-540, 2013.

Neu, U., Akperov, M. G., Bellenbaum, N., Benestad, R., Blender, R., Caballero, R., Cocozza, A., Dacre, H. F., Feng, Y., Fraedrich, K., Grieger, J., Gulev, S., Hanley, J., Hewson, T., Inatsu, M., Keay, K., Kew, S. F., Kindem, I., Leckebusch, G. C., Liberato, M. L. R., Lionello, P., Mokhov, I. I., Pinto, J. G., Raible, C. C., Reale, M., Rudeva, I., Schuster, M., Simmonds, I., Sinclair, M., Sprenger, M., Tilinina, N. D., Trigo, I. F., Ulbrich, S., Ulbrich, U., Wang, X. L., and Wernli, H.: IMILAST: a community effort to intercompare extratropical cyclone detection and tracking algorithms, B. Am. Meteor. Soc., 94, 529-547, doi:10.1175/BAMS-D-11-00154.1, 2013.

Olsen, M. and Stanford, J.: Evidence of stratosphere-to-troposphere transport within a mesoscale model and Total Ozone Mapping Spectrometer total ozone, J. Geophys. Res., 106, 27323-27334, 2001.

Poulida, O., Dickerson, R., and Heymsfield, A.: Stratospheretroposphere exchange in a midlatitude mesoscale convective complex 1. Observations, J. Geophys. Res., 101, 6823-6836, doi:10.1029/95JD03523, 1996.

Reiter, E. R.: Stratospheric-tropospheric exchange processes, Rev. Geophys., 13, 459-474, doi:10.1029/RG013i004p00459, 1975.

Shapiro, M. A.: Turbulent mixing within tropopause folds as a mechanism for the exchange of chemical constituents between the stratosphere and troposphere, J. Atmos. Sci., 37, 994-1004, doi:10.1175/1520-0469(1980)037<0994:TMWTFA>2.0.CO;2, 1980.

Sigmond, M., Meloen, J., and Siegmund, P. C.: Stratospheretroposphere exchange in an extratropical cyclone, calculated with a Lagrangian method, Ann. Geophys., 18, 573-582, doi:10.1007/s00585-000-0573-1, 2000.

Škerlak, B., Sprenger, M., and Wernli, H.: A global climatology of stratosphere-troposphere exchange using the ERA-Interim data set from 1979 to 2011, Atmos. Chem. Phys., 14, 913-937, doi:10.5194/acp-14-913-2014, 2014.

Škerlak, B., Sprenger, M., Pfahl, S., Tyrlis, E., and Wernli, H.: Tropopause folds in ERA-Interim: Global climatology and relation to extreme weather events, J. Geophys. Res.-Atmos., 120, 4860-4877, 2015.

Spaete, P., Johnson, D. R., and Schaack, T. K.: Stratospherictropospheric mass exchange during the Presidents' Day Storm., Mon. Weather Rev., 122, 424-439, 1994. 
Sprenger, M., Croci Maspoli, M., and Wernli, H.: Tropopause folds and cross-tropopause exchange: a global investigation based upon ECMWF analyses for the time period March 2000 to February 2001, J. Geophys. Res., 108, 8518, doi:10.1029/2002JD002587, 2003.

Sprenger, M., Wernli, H., and Bourqui, M.: Stratospheretroposphere exchange and its relation to potential vorticity streamers and cutoffs near the extratropical tropopause, J. Atmos. Sci., 64, 1587-1602, doi:10.1175/JAS3911.1, 2007.

Stevenson, D. S., Dentener, F. J., Schultz, M. G., Ellingsen, K., van Noije, T. P. C., Wild, O., Zeng, G., Amann, M., Atherton, C. S., Bell, N., Bergmann, D. J., Bey, I., Butler, T., Cofala, J., Collins, W. J., Derwent, R. G., Doherty, R. M., Drevet, J., Eskes, H. J., Fiore, A. M., Gauss, M., Hauglustaine, D. A., Horowitz, L. W., Isaksen, I. S. A., Krol, M. C., Lamarque, J.F., Lawrence, M. G., Montanaro, V., Müller, J.-F., Pitari, G., Prather, M. J., Pyle, J. A., Rast, S., Rodriguez, J. M., Sanderson, M. G., Savage, N. H., Shindell, D. T., Strahan, S. E., Sudo, K., and Szopa, S.: Multimodel ensemble simulations of present-day and near-future tropospheric ozone, J. Geophys. Res., 111, D08301, doi:10.1029/2005JD006338, 2006.

Stohl, A., Bonasoni, P., Cristofanelli, P., Collins, W., Feichter, J., Frank, A., Forster, C., Gerasopoulos, E., Gäggeler, H., James, P., Kentarchos, A. S., Kromp-Kolb, H., Krüger, B., Land, C., Meloen, J., Papayannis, A., Priller, A., Seibert, P., Sprenger, M., Roelofs, G. J., Scheel, H. E., Schnabel, C., Siegmund, P., Tobler, L., Trickl, T., Wernli, H., Wirth, V., Zanis, P., and Zerefos, C.: Stratosphere-troposphere exchange: a review, and what we have learned from STACCATO, J. Geophys. Res., 108, 8516, doi:10.1029/2002JD002490, 2003.

Taylor, K. E., Stouffer, R. J., and Meehl, G. A.: An overview of CMIP5 and the experiment desing, B. Am. Meteorol. Soc., 93, 485-498, doi:10.1175/BAMS-D-11-00094.1, 2012.
Traub, M. and Lelieveld, J.: Cross-tropopause transport over the eastern Mediterranean, J. Geophys. Res., 108, 4712, doi:10.1029/2003JD003754, 2003.

Wernli, H. and Bourqui, M.: A Lagrangian "1-year climatology" of (deep) cross-tropopause exchange in the extratropical Northern Hemisphere, J. Geophys. Res., 107, 4021, doi:10.1029/2001JD000812, 2002.

Wernli, H. and Davies, H.: A Lagrangian-based analysis of extratropical cyclones. 1: The method and some applications, Q. J. Roy. Meteor. Soc., 123, 467-489, 1997.

Wernli, H. and Schwierz, C.: Surface cyclones in the ERA40 dataset (1958-2001). Part I: Novel identification method and global climatology, J. Atmos. Sci., 63, 2486-2507, doi:10.1175/JAS3766.1, 2006.

Whiteway, J., Pavelin, E., Busen, R., Hacker, J., and Vosper, S.: Airborne measurements of gravity wave breaking at the tropopause, Geophys. Res. Lett., 30, 2070, doi:10.1029/2003GL018207, 2003.

Wirth, V.: Diabatic heating in an axisymmetric cut-off cyclone and related stratosphere-troposphere exchange, Q. J. Roy. Meteor Soc., 121, 127-147, doi:10.1002/qj.49712152107, 1995.

Wirth, V. and Egger, J.: Diagnosing extratropical synoptic-scale stratosphere-troposphere exchange: a case study, Q. J. Roy. Meteor. Soc., 125, 635-655, doi:10.1002/qj.49712555413, 1999.

Zierl, B. and Wirth, V.: The influence of radiation on tropopause behavior and stratosphere-troposphere exchange in an upper tropospheric anticyclone, J. Geophys. Res., 102, 23883-23894, doi:10.1029/97JD01667, 1997. 